\title{
Neoadjuvant chemotherapy for pancreatic cancer: Effects on cancer tissue and novel perspectives (Review)
}

\author{
HIDEHIRO TAJIMA, ISAMU MAKINO, YOSHINAO OHBATAKE, SHINICHI NAKANUMA, \\ HIRONORI HAYASHI, HISATOSHI NAKAGAWARA, TOMOHARU MIYASHITA, \\ HIROYUKI TAKAMURA and TETSUO OHTA \\ Department of Gastroenterological Surgery, Division of Cancer Medicine, \\ Graduate School of Medicine Science, Kanazawa University, Kanazawa 920-8641, Japan \\ Received November 28, 2015; Accepted February 17, 2017
}

DOI: $10.3892 / \mathrm{ol} .2017 .6008$

\begin{abstract}
Chemotherapy for pancreatic cancer has diversified following the addition of more treatment regimens; however, in spite of this, pancreatic cancer remains a fatal disease. Preoperative (neoadjuvant) chemotherapy (NAC) or neoadjuvant chemoradiation therapy (NACRT) has been developed and implemented. For patients with borderline resectable pancreatic cancer (BRPC) and locally advanced pancreatic cancer (LAPC), a number of clinical trials have been conducted; NACRT was demonstrated to improve resectability, $\mathrm{R} 0$ resection rate, overall survival rate, disease-free survival rate and even an LAPC and BRPC survival advantage over NAC. However, from the knowledge obtained from resected specimens following preoperative treatment, residual pancreatic cancer tissues following NAC are rich in chemoresistant cancer stem-like cells and epithelial-mesenchymal transition (EMT) markers. Conversely, metformin, angiotensin receptor blocker, statins and low-dose paclitaxel are well-known as drugs that inhibit EMT, which is associated with cancer stem cell-like characteristics. Although clinical effectiveness is unlikely to be achieved using one of these as an anticancer agent, it is reasonable to use these drugs for patients with comorbidities in the treatment of pancreatic cancer. Furthermore, gemcitabine (GEM) affects antitumor immunity by stimulating the expression of major histocompatibility complex class I-related chain A on the surface of cancer cells to enhance the cytotoxicity of natural killer cells. Considering EMT and antitumor immunity, there is a possibility that GEM and nanoparticle albumin-bound paclitaxel therapy is the most suitable regimen for treating pancreatic cancer. However, even as preoperative treatment
\end{abstract}

Correspondence to: Dr Hidehiro Tajima, Department of Gastroenterological Surgery, Division of Cancer Medicine, Graduate School of Medicine Science, Kanazawa University, 13-1 Takaramachi, Kanazawa 920-8641, Japan

E-mail: hidetaji@staff.kanazawa-u.ac.jp

Key words: pancreatic cancer, neoadjuvant chemotherapy, neoadjuvant chemoradiotherapy, epithelial-mesenchymal transition progresses, R0 resection is the most important factor for the long-term survival of pancreatic cancer patients.

\section{Contents}

1. Introduction

2. Neoadjuvant treatment

3. Effect of preoperative therapy on pancreatic cancer tissues

4. Conclusions

\section{Introduction}

Pancreatic cancer is a fatal disease with an overall 5-year survival rate of $<5 \%(1,2)$. For patients with localized disease, surgery is the only method of treatment that provides long-term benefits. Curative (R0) resection has been identified to be one of the key factors influencing the survival of patients with pancreatic cancer $(3,4)$. Esposito et al $(5)$ reported that the majority of pancreatic cancer resections include margin involvement $(\mathrm{R} 1)$ resection and pathological reporting is important. Indeed, even in patients who undergo resection, the 5-year survival rate is poor at between 7 and 24\%, whereas the median survival time is $\sim 1$ year in the majority of series, indicating that surgery alone is inadequate. A number of surgeons have attempted radical pancreatic resection, comprising wide lymphadenectomy and removal of the extrapancreatic nerve plexus, to improve outcomes (6-10). However, no improvement in the prognosis of pancreatic cancer has been achieved. Furthermore, Nimura et al (11) reported that extended lymphadenectomy had no effect on improving the prognosis in pancreatic head carcinoma. These disappointing results are possibly attributable to early vascular dissemination, because the majority of patients have metastases that are present at the time of diagnosis (12). This hypothesis underpins the investigation of adjuvant chemotherapy and chemoradiotherapy (CRT) following surgery. Adjuvant chemotherapy or CRT has been performed on the basis of 5-fluorouracil (5-FU)containing regimens since the $1980 \mathrm{~s}$, and its usefulness has been reported (13-18). More recently, Oettle et al (19) reported that adjuvant chemotherapy with gemcitabine (GEM) led to 
a statistically significant improvement in the OS (overall survival) rate. Furthermore, results of the Japan Adjuvant Study Group of Pancreatic Cancer 01 study indicated that S-1, an oral fluoropyrimidine analogue, confers a significantly improved OS rate and recurrence-free survival rate following pancreatic cancer resection compared with GEM (20). A major drawback of adjuvant therapy for pancreatic cancer is marked and consistent failure of between 20 and $30 \%$ of patients to receive the designated therapy as a result of postoperative complications, delayed surgical recovery, patient refusal, comorbidity or early disease recurrence $(16,21,22)$. These challenges can be overcome in certain cases by administering preoperative (neoadjuvant) therapy, so that an increased number of patients may receive potentially beneficial adjuvant treatment. Other theoretical advantages of this approach include the early treatment of micrometastases, delaying surgery, thereby sparing those patients who already have occult metastases from the morbidity and mortality of major surgery if disseminated disease becomes apparent at the time of reassessment, decreased risk of intraoperative tumor seeding, improved treatment tolerance compared with postoperative therapy, and decreased overall treatment time (23). Therefore, in recent years, neoadjuvant chemotherapy (NAC) and neoadjuvant chemoradiation therapy (NACRT) have been attempted, seeking further improvement in treatment results for pancreatic cancer. However, due to the lack of randomized studies, the optimal performance of neoadjuvant treatment remains a matter of debate. In the present review, the effectiveness of preoperative treatment and the impact of preoperative treatment on pancreatic cancer tissues are examined.

\section{Neoadjuvant treatment}

The National Comprehensive Cancer Network (NCCN) guidelines endorsed by the American Hepatopancreatobiliary Association/Society of Surgical Oncology/Society for Surgery of the Alimentary Tract system (24) have been used for the treatment of pancreatic cancer worldwide. According to the NCCN guidelines, only $20 \%$ of patients are diagnosed with resectable pancreatic cancer, $40 \%$ of patients have metastatic disease, and the remaining $40 \%$ have locally advanced pancreatic cancer in the form of either borderline resectable pancreatic cancer (BRPC) or locally advanced pancreatic cancer (LAPC) (25). Neoadjuvant treatment is often considered separately from resectable pancreatic cancer and BRPC and/or LAPC. Furthermore, patients with BRPC and LAPC have $\sim 50 \%$ chance of curative resection compared with patients with resectable pancreatic cancer (26-29).

Recent meta-analyses have provided evidence of BRPC and LAPC being advantageous over neoadjuvant strategies (30): i) Neoadjuvant treatment may avoid handicapping postoperative surgical complications (31); ii) neoadjuvant treatment may assist in avoiding unnecessary major abdominal surgery during treatment; iii) chemotherapeutic agents have an improved effect owing to increased vascularization and subsequent drug delivery to neoplastic tissues without surgical trauma (32); iv) for BRPC and LAPC patients, neoadjuvant therapy leads to down-staging of the disease and increasing the rate of $\mathrm{R} 0$ resections (26,33-39); v) a number of studies identified a decreased incidence of anastomotic fistulas following neoadjuvant treatment (40-43); and xi) analyses of the costs of various treatments for pancreatic cancer identified an economic advantage for neoadjuvant treatment regimens $(40,44)$. As the most significant factor predicting long-term survival in pancreatic cancer patients is an $\mathrm{R} 0$ resection, the most important factor of neoadjuvant treatment for LAPC and BRPC patients is increasing the rate of $\mathrm{R} 0$ resections. The results of a number of clinical trials of neoadjuvant treatment for LAPC and BRPC have been reported. For instance, Lee et al (43) reported 43 patients with LAPC and BRPC treated with a combination of GEM and capecitabine. In the LAPC group, 24\% underwent surgical resection with $83.3 \%$ having $\mathrm{R} 0$ resections. In the BRPC group, $61 \%$ underwent surgical resection with $81.8 \%$ having R0 resections. Sahora et al (44) reported the results of a Phase II study of NAC for LAPC and BRPC using GEM plus docetaxel; the overall resection rate was $32 \%$ with $87.5 \%$ having $\mathrm{R} 0$ resections and the median survival time of resected case was 16 months.

Conroy et al (45) reported the results of a Phase III study on the efficacy of 5-FU, leucovorin, irinotecan and oxaliplatin (FOLFIRINOX) chemotherapy for LAPC and metastatic pancreatic cancer, and demonstrated the significant superiority of FOLFIRINOX over GEM alone with respect to the OS rate, progression-free survival (PFS) rate and overall response rate. On the basis of the results of this Actions Concertées dans les Cancers Colo-Rectaux et Digestifs (ACCORD) trial, neoadjuvant therapy with FOLFIRINOX is currently available and leads to the most consistent results for the treatment of metastatic pancreatic cancer and LAPC (45). There are a number of retrospective studies of NAC using FOLFIRINOX for LAPC and BRPC (34,46-49). Hosein et al (34) performed a retrospective study of NAC using FOLFIRINOX for LAPC with a $62.5 \%$ R0 resection rate, $83 \%$ 1-year PFS rate and 100\% 1-year OS rate. Ferrone et al (49) reported that, in spite of post-FOLFIRINOX imaging suggesting continued unresectability, $92 \%$ of patients underwent R0 resection. Furthermore, compared with no NAC, FOLFIRINOX resulted in a significantly longer operation time (393 vs. $300 \mathrm{~min}$ ) and blood loss (600 vs. $400 \mathrm{ml})$, but significantly decreased operative morbidity (36 vs. 63\%) and no postoperative pancreatic fistulas (49). From these results, FOLFIRINOX as a NAC is safe and effective for LAPC and BRPC; however, the long-term results remain unclear. Randomized control trials are warranted.

Nanoparticle albumin-bound (nab-)paclitaxel in combination with GEM has emerged as a novel treatment option for patients with metastatic pancreatic cancer on the basis of its superiority over GEM. The phase III Metastatic Pancreatic Adenocarcinoma Clinical Trial demonstrated the superior efficacy of nab-Paclitaxel and GEM compared with GEM alone for all trial endpoints, including the primary endpoint of overall survival in patients with metastatic pancreatic cancer treated to disease progression (50). Nab-paclitaxel and GEM treatment has also been used in a neoadjuvant setting, and effectiveness has been reported $(51,52)$.

Studies on CRT for LAPC with 5-FU-based regimens have been published since the 1980s and survival prolongation has been demonstrated compared with radiation alone (53). The theoretical hypothesis on which CRT is based is that, whereas chemotherapy enables management of microdisseminated disease and also acts as a radiation sensitizer, radiotherapy 
may have a marked impact on local disease management. However, $30 \%$ of patients with LAPC develop distant metastases during the early cycles of treatment and radiotherapy may increase distant metastases $(30,54)$. Therefore, the combination of chemotherapy and radiotherapy is essential. Evidence to support the use of NACRT for LAPC is accumulating $(30,35)$. These data demonstrate that NACRT improves resectability, R0 resection rate, OS rate and disease-free survival (DFS) rate, and reveal a survival advantage to patients with LAPC and BRPC compared with NAC.

NAC strategies have also been considered in association with resectable pancreatic cancer. For instance, Heinrich et al $(55,56)$ published Phase II and III trials of NAC with GEM vs. GEM and oxaliplatin treatment for resectable pancreatic cancer. A number of small trials have reported the use of NAC or NACRT for treating resectable pancreatic cancer $(23,57,58)$; however, no data on OS and DFS have been reported. Therefore, only surgical resection with negative margins may offer a chance of long-term survival, and NAC or NACRT will be necessary for treating LAPC and BRPC. Consideration of the regimen to be used and the duration of preoperative treatment are required. Furthermore, it is necessary to consider whether or not preoperative treatment should be administered for resectable pancreatic cancer.

\section{Effect of preoperative therapy on pancreatic cancer tissues}

From resected specimens following preoperative treatment, the effect of chemotherapy or CRT on pancreatic cancer tissue may be determined. Evans et al (59) published an appropriate grading system for the effect of CRT that has been widely used for pancreatic cancer. Pancreatic ductal adenocarcinoma tissues are characterized by universal desmoplastic reaction, featuring a fibrotic stroma and dysfunctional hypoperfused vascularity (60). The stroma is composed of extracellular matrix proteins, including collagen, hyaluronic acid, and secreted acidic and cysteine-rich proteins, and cellular elements, including cancer-associated fibroblasts (CAFs) (51). This altered stroma has been implicated in cancer development and maintenance, and also in the poor sensitivity of pancreatic cancer to chemotherapeutics. Furthermore, the interaction between carcinoma cells and stromal cells, including CAFs, influence stromal formation, invasion and metastasis $(60,61)$.

Epithelial-mesenchymal transition (EMT) of tumor cells induced by stromal cells has been reported (62-64). EMT is a key event in tumor invasion and metastasis, whereby epithelial cell layers lose polarity and cell-cell contacts, and undergo marked cytoskeletal remodeling (65). Chemotherapy and radiotherapy are known to induce apoptotic cell death in malignant tumors (66). Additionally, it has been reported that anticancer treatments may also induce EMT in cancer cells, which may serve an important role in the aggressive behavior of tumors (67-69). Furthermore, EMT is induced in pancreatic cancer cells irrespective of whether the patient receives chemotherapy, and the interaction between cancer cells and stromal cells serves a crucial role in pancreatic cancer (70).

Low-dose paclitaxel (71-74), metformin (75-77), angiotensin receptor blocker $(\mathrm{ARB})(61,78)$, statins $(79,80)$ and histone deacetylase inhibitors (HDACis) $(81,82)$ have all been indicated as agents that can inhibit the EMT of tumor cells or activation of stromal cells. There are a number of studies investigating the effects of these drugs and cancer treatments: For instance, metformin has been epidemiologically demonstrated to suppress tumor metastasis $(83,84)$, whereas Nakai et al $(85)$ demonstrated that inhibition of the renin-angiotensin system affects the prognosis of patients with advanced pancreatic cancer receiving GEM. A number of studies have focused on the inhibition of tumor EMT and stromal cell activation using paclitaxel $(74,86,87)$. The results of these studies are consistent with the observation of tumor shrinkage and a decrease in stroma in tumors treated with nab-paclitaxel and GEM $(88,89)$. Finally, HDACis have been tested in clinical trials of pancreatic cancer treatment combined with valproic acid and oral S-1 (90).

Chemotherapy for treating pancreatic cancer has diversified by adding further regimens including FOLFIRINOX and nab-paclitaxel plus GEM, but curing pancreatic cancer using chemotherapy or CRT remains difficult. Carcinoma cells within a tumor are heterogeneous, indicating that certain carcinoma cells may have slightly different properties from those of others (91). A concept has been proposed stating that a specific subpopulation of carcinoma cells with stem cell-like properties are responsible for tumor growth, whereas other carcinoma cells do not contribute to tumor expansion (92). In our previous study, it was demonstrated that residual pancreatic cancer tissues following preoperative chemotherapy were rich in chemoresistant cancer stem cells with the marker cluster of differentiation (CD)44 (70). A number of lines of evidence suggest an association between EMT and cancer stem cell characteristics in pancreatic cancer (93). Therefore, it may not be an exaggeration to say that suppression of EMT is the key for the treatment of pancreatic cancer.

Conversely, it has been reported that GEM affects antitumor immunity. Major histocompatibility complex class I-related chain A (MICA) expressed on the surface of cancer cells functions as a ligand for natural killer group 2 member D (NKG2D), an immune-receptor expressed on natural killer (NK) cells, and CD8 and $\gamma \delta$ T cells. The interaction between MICA and NKG2D stimulates NK cell-mediated cytotoxicity, and GEM stimulates the expression of MICA on the surface of cancer cells to enhance the cytotoxicity of NK cells (94). Furthermore, Miyashita et al (95) detected significantly increased immunohistochemical expression of MICA on the surface of pancreatic cancer cells and NKG2D-positive cells surrounding cancer cells in pancreatic cancer tissues following preoperative chemotherapy with GEM and oral S-1 compared with in untreated cancer tissues. However, cancer cells promote immune escape by ectodomain shedding of MICA and produce soluble MICA that competitively inhibits NKG2D expression on the surface of NK cells. The key molecule that activates the shedding protease, including a disintegrin and metalloproteinases 9,10 and 17 , is considered to be transforming growth factor (TGF)- $\beta$ (96-98). Therefore, treatments that inhibit TGF- $\beta$ are important in antitumor immunity (99). Metformin $(100,101)$ and ARB $(61,78,102)$ are well-known as drugs that inhibit TGF- $\beta$, in addition to inhibition of EMT. Although clinical effectiveness is unlikely to be achieved using one of these as an anticancer agent, it is reasonable to use these drugs for patients with comorbidities, including diabetes, 
hypertension and hyperlipidemia, in the treatment of pancreatic cancer. When considering EMT and antitumor immunity, GEM and nab-paclitaxel therapy is currently the most suitable regimen for the treatment of pancreatic cancer.

\section{Conclusions}

Chemotherapy for pancreatic cancer has diversified following the addition of further regimens, but patient prognosis remains poor. Therefore, the possibility of prognostic improvement using NAC or NACRT is being actively investigated. According to the results of several clinical trials, NACRT improves resectability, $\mathrm{R} 0$ resection rate, OS rate and DFS rate, and suggests a survival advantage in patients with LAPC and BRPC compared with patients with NAC. For resectable pancreatic cancer, the necessity of preoperative treatment remains controversial.

It is beneficial to obtain various results from resected specimens following preoperative treatment. Residual pancreatic cancer tissues following preoperative chemotherapy are rich in chemoresistant cancer stem-like cells and EMT markers. Metformin, ARB, statins and low-dose paclitaxel are well known drugs that inhibit EMT and TGF- $\beta$. Although clinical effectiveness is unlikely to be achieved using one of these as an anticancer agent, it is reasonable to use these drugs for patients with comorbidities in the treatment of pancreatic cancer. Furthermore, GEM affects the antitumor immunity by stimulating the expression of MICA on the surface of cancer cells to enhance the cytotoxicity of NK cells. When considering EMT and antitumor immunity, there is the possibility that GEM and nab-paclitaxel therapy is the most suitable regimen for the treatment of pancreatic cancer. However, even as perioperative treatment progresses, $\mathrm{R} 0$ resection is the most important factor in the long-term survival time of patients with pancreatic cancer.

\section{References}

1. Ministry of Health, Labour and Welfare: The Dynamic Statistics of the Population in 2014 (In Japanese). http://www.mmjp. or.jp/kawakami-clinic/data/h26gan.htm. Accessed November 1, 2015.

2. Ishii H, Furuse J, Boku N, Okusaka T, Ikeda M, Ohkawa S, Fukutomi A, Hamamoto Y, Nakamura K and Fukuda H; JCOG Gastrointestinal Oncology Study Group: Phase II study of gemcitabine chemotherapy alone for locally advanced pancreatic carcinoma: JCOG0506. Jpn J Clin Oncol 40: 573-579, 2010.

3. Wagner M, Redaelli C, Lietz M, Seiler CA, Friess H and Bücher MW: Curative resection is the single most important factor determining outcome in patients with pancreatic adenocarcinoma. Br J Surg 91: 586-594, 2004.

4. Verbeke CS and Menon KV: Redefining resection margin status in pancreatic cancer. HPB (Oxford) 11: 282-289, 2009.

5. Esposito I, Kleeff J, Bergmann F, Reiser C, Herpel E, Friess H, Schirmacher P and Büchler MW: Most pancreatic cancer resections are R1 resections. Ann Surg Oncol 15: 1651-1660, 2008.

6. Nagakawa T, Kurachi M, Konishi K and Miyazaki I: Translateral retroperitoneal approach in radical surgery for pancreatic carcinoma. Jpn J Surg 12: 229-233, 1982.

7. Nagakawa T, Nagamori M, Futakami F, Tsukioka Y, Kayahara M, Ohta T, Ueno K and Miyazaki I: Result of extensive surgery for pancreatic carcinoma. Cancer 77: 640-645, 1996.

8. Kitagawa H, Tajima H, Nakagawara H, Makino I, Miyashita T, Shoji M, Nakanuma S, Hayashi N, Takamura H, Ohta T and Ohtake H: En bloc vascular resection for the treatment of borderline resectable pancreatic head carcinoma. Mol Clin Oncol 2: 369-374, 2014.
9. Hirano S, Kondo S, Hara T, Ambo Y, Tanaka E, Shichinohe T, Suzuki O and Hazama K: Distal pancreatectomy with en bloc celiac axis resection for locally advanced pancreatic body cancer: Long-term results. Ann Surg 246: 46-51, 2007.

10. Kitagawa H, Tajima H, Nakagawara H, Makino I, Miyashita T, Terakawa H, Nakanuma S, Hayashi H, Takamura $\mathrm{H}$ and Ohta T: A modification of radical antegrade modular pancreatosplenectomy for adenocarcinoma of the left pancreas: Significance of en bloc resection including the anterior renal fascia. World J Surg 38: 2448-2454, 2014.

11. Nimura Y, Nagino M, Takao S, Takada T, Miyazaki K, Kawarada Y, Miyagawa S, Yamaguchi A, Ishiyama S, Takeda Y, et al: Standard versus extended lymphadenectomy in radical pancreatoduodenectomy for ductal adenocarcinoma of the head of the pancreas: Long-term results of a Japanese multicenter randomized controlled trial. J Hepatobiliary Pancreat Sci 19: 230-241, 2012.

12. Evans DB, Abbruzzese JL and Willett CG: Cancer of the pancreas. In: De Vita, Hellman S, Rosenberg SA, (eds). Cancer: Principles and practice of oncology. 6th (ed). Philadelphia: Lippincott, Williams and Wilkins, 1126-1161, 2001.

13. Kalser $\mathrm{MH}$ and Ellenberg SS: Pancreatic cancer. Adjuvant combined radiation and chemotherapy following curative resection. Arch Surg 120: 899-903, 1985.

14. Bakkevold KE, Arnesjø B, Dahl O and Kambestad B: Adjuvant combination chemotherapy (AMF) following radical resection of carcinoma of the pancreas and papilla of Vater-results of a controlled, prospective, randomised multicentre study. Eur J Cancer 29A: 698-703, 1993

15. Lygidakis NJ and Stringaris K: Adjuvant therapy following pancreatic resection for pancreatic duct carcinoma: A prospective randomized study. Hepatogastroenterology 43: 671-680, 1996.

16. Klinkenbijl JH, Jeekel J, Sahmoud T, van Pel R, Couvreur ML, Veenhof CH, Arnaud JP, Gonzalez DG, de Wit LT, Hennipman A and Wils J: Adjuvant radiotherapy and 5-fluorouracil after curative resection of cancer of the pancreas and periampullary region: Phase III trial of the EORTC gastrointestinal tract cancer cooperative group. Ann Surg 230: 776-784, 1999.

17. Lygidakis NJ, Sgourakis G, Georgia D, Vlachos L and Raptis S: Regional targeting chemoimmunotherapy in patients undergoing pancreatic resection in an advanced stage of their disease: A prospective randomized study. Ann Surg 236: 806-813, 2002

18. Neoptolemos JP, Stocken DD, Friess H, Bassi C, Dunn JA, Hickey $\mathrm{H}$, Beger $\mathrm{H}$, Fernandez-Cruz L, Dervenis C, Lacaine $\mathrm{F}$, et al: A randomized trial of chemoradiotherapy and chemotherapy after resection of pancreatic cancer. $\mathrm{N}$ Engl J Med 350: 1200-1210, 2004.

19. Oettle H, Post S, Neuhaus P, Gellert K, Langrehr J, Ridwelski K, Schramm H, Fahlke J, Zuelke C, Burkart C, et al: Adjuvant chemotherapy with gemcitabine vs observation in patients undergoing curative-intent resection of pancreatic cancer: A randomized controlled trial. JAMA 297: 267-277, 2007.

20. Fukutomi A, Uesaka K, Boku N, Kanemoto H, Konishi M, Matsumoto I, Kaneoka Y, Shimizu Y, Nakamori S, Sakamoto H, et al: JASPAC 01: Randomized phase III trial of adjuvant chemotherapy with gemcitabine versus $S-1$ for patients with resected pancreatic cancer. J Clin Oncol 31 (Suppl): abstr 4008, 2013.

21. Spitz FR, Abbruzzese JL, Lee JE, Pisters PW, Lowy AM, Fenoglio CJ, Cleary KR, Janjan NA, Goswitz MS, Rich TA and Evans DB: Preoperative and postoperative chemoradiation strategies in patients treated with pancreaticoduodenectomy for adenocarcinoma of the pancreas. J Clin Oncol 15: 928-937, 1997.

22. Yeo CJ, Abrams RA, Grochow LB, Sohn TA, Ord SE,Hruban RH, Zahurak ML, Dooley WC, Coleman J, Sauter PK, et al: Pancreaticoduodenectomy for pancreatic adenocarcinoma: Postoperative adjuvant chemoradiation improves survival. A prospective, single-institution experience. Ann Surg 225: 621-636, 1997.

23. Tajima H, Ohta T, Kitagawa H, Okamoto K, Sakai S, Makino I, Kinoshita J, Furukawa H, Nakamura K, Hayashi H, et al: Pilot study of neoadjuvant chemotherapy with gemcitabine and oral S-1 for resectable pancreatic cancer. Exp Therap Med 3: 787-792, 2012.

24. Vauthey JN and Dixon E: AHPBA/SSO/SSAT consensus conference on resectable and borderline resectable pancreatic cancer: Rationale and overview of the conference. Ann Surg Oncol 16: 1725-1726, 2009. 
25. Zakharova OP, Karmazanovsky GG and Egorov VI: Pancreatic adenocarcinoma: Outstanding problems. World J Gastrointest Surg 4: 104-113, 2012

26. Varadhachary GR, Tamm EP, Abbruzzese JL, Xingo HQ, Crane CH, Wang H, Lee JE, Pisters PW, Evans DB and Wolff RA Borderline resectable pancreatic cancer: Definitions, management, and role of preoperative therapy. Ann Surg Oncol 13: 1035-1046, 2006.

27. Moore GE, Sako Y and Thoms LB: Radical pancreatoduodenectomy with resection and reanastomosis of the superior mesenteric vein. Surgery 30: 550-553, 1951

28. Siriwardana HP and Siriwardena AK: Systematic review of outcome of synchronous portal-superior mesenteric vein resection during pancreatectomy for cancer. Br J Surg 93: 662-673, 2006.

29. Glanemann M, Shi B, Liang F, Sun XG, Bahra M, Jacob D, Neumann U and Neuhaus P: Surgical strategies for treatment of malignant pancreatic tumors: Extended, standard of local surgery? World J Surg Oncol 6: 123, 2008.

30. Polistina F, Di Natale G, Bonciarelli G, Ambfosino G and Frego M: Neoadjuvant strategies for pancreatic cancer. World J Gastroenterol 20: 9374-9383, 2014.

31. Lim KH, Chung E, Khan A, Cao D, Linehan D, Ben-Josef E and Wang-Gilliam A: Neoadjuvant therapy of pancreatic cancer: The emerging paradigm? Oncologist 17: 192-200, 2012.

32. Assifi MM, Lu X, Eibl G, Reber HA, Li G and Hines OJ: Neoadjuvant therapy in pancreatic adenocarcinoma: A meta-analysis of phase II trials. Surgery 150: 466-473, 2011.

33. Satoi S, Yanagimoto $H$, Toyokawa $H$, Takahashi $K$, Matsui $Y$, Kitade H, Mergental H, Tanigawa N, Takai S and Kwon AH: Surgical results after preoperative chemoradiation therapy for patients with pancreatic cancer. Pancreas 38: 282-288, 2009

34. Hosein PJ, Macintyre J, Kawamura C, Maldonado JC, Ernani V, Loaiza-Bonilla A, Narayanan G, Ribeiro A, Portelance L, Merchan JR, et al: A retrospective study of neoadjuvant FOLFIRINOX in unresectable of borderline resectable locally advanced pancreatic adenocarcinoma. BMC Cancer 12: 199, 2012

35. Gillen S, Schuster T, Meyer Zum Büschenfelde C, Friess H and Kleeff J: Postoperative/neoadjuvant therapy in pancreatic cancer: A systemic review and meta-analysis of response and resection percentages. PLoS Med 7: e1000267, 2010.

36. Chandler NM, Cante JJ, Stuart KE and Callery MP: Preoperative chemoradiation in resectable pancreatic cancer. J Hepatobiliary Pancreat Surg 10: 61-66, 2003.

37. Evans DB: Preoperative chemoradiation for resectable and locally advanced adenocarcinoma of the pancreas. J Gastrointest Surg 5: 2-5, 2001

38. Russo S, Chabot J and Saif MW: Resectable pancreatic cancer: Is surgery the best first step? JOP 13: 151-154, 2012.

39. Abbot DE, Tzeng CW, Merkow RP, Cantor SB, Chang GJ, Katz MH, Bentrem DJ, Bilimoria KY, Crane $\mathrm{CH}$ Varadhachary GR, et al: The cost-effectiveness of neoadjuvant chemoradiation is superior to a surgery-first approach in the treatment of pancreatic head adenocarcinoma. Ann Surg Oncol 20 (Suppl 3): S500-S508, 2013.

40. Louvet C, Labianca R, Hammel P, Lledo G, Zampino MG, André T, Zaniboni A, Ducreux M, Aitini E, Taïeb J, et al: Gemcitabine in combination with oxaliplatin compared with gemcitabine alone in locally advanced or metastatic pancreatic cancer: Results of a GERCOR and GISCAD phase III trial. J Clin Oncol 23: 3509-3516, 2005.

41. Kindler HI, Niedzwiecki D, Hollis D, Sutherland S, Schrag D, Hurwitz H, Innocenti F, Mulcahy MF, O'Reilly E, Wozniak TF, et al: Gemcitabine plus bevacizumab compared with gemcitabine plus placebo in patients with advanced pancreatic cancer: Phase III trial of the Cancer and Leukemia Group B (CALGB 80303). J Clin Oncol 28: 3617-3622, 2010.

42. Andriulli A, Festa V, Botteri E, Valvno MR, Koch M, Bassi C, Maisonneuve P and Sebastiano PD: Neoadjuvant/preoperative gemcitabine for patients with localized pancreatic cancer: A meta-analysis of prospective studies. Ann Surg Oncol 19: $1644-1662,2012$

43. Lee JL, Kim SC, Kim JH, Lee SS, Kim TW, Park DH, Seo DW, Lee SK, Kim MH, Kim JH, et al: Prospective efficacy and safety study of neoadjuvant gemcitabine with capecitabine combination chemotherapy for borderline-resectable or unresectable locally advanced pancreatic adenocarcinoma. Surgery 152: 851-862, 2012

44. Sahora K, Kuehrer I, Schindl M, Koelblinger C, Goetzinger P and Gnant M: NeoGemTax: Gemcitabine and docetaxel as neoadjuvant treatment for locally advanced nonmetastasized pancreatic cancer. World J Surg 35: 1580-1589, 2011.
45. Conroy T, Desseigne F, Ychou M, Bouché O, Guimbaud R, Bécouarn Y, Adenis A, Raoul JL, Gourgou-Bourgade S, de la Fouchardière $C$, et al: FOLFIRINOX versus gemcitabine for metastatic pancreatic cancer. N Eng J Med 364: 1817-1825, 2011.

46. Christians KK, Tsai S, Mahmoud A, Ritch P, Thomas JP, Wiebe L, Kelly T, Erickson B, Wang H, Evans DB and George B: Neoadjuvant FOLFIRINOX for borderline resectable pancreas cancer: A new treatment paradigm? Oncologist 19: 266-274, 2014

47. Paniccia A, Edil BH, Schulick RD, Byers JT, Meguid C, Gajdos C and McCarter MD: Neoadjuvant FOLFIRINOX application in borderline resectable pancreatic adenocarcinoma: A retrospective Cohort study. Med 93: e198, 2014.

48. Blazer M, Wu C, Goldberg RM, Phillips G, Schmidt C, Muscarella P, Wuthrick E, Williams TM, Reardon J, Ellison EC, et al: Neoadjuvant modified (m) FOLFIRINOX for locally advanced unresectable (LAPC) and borderline resectable (BRPC) adenocarcinoma of the pancreas. Ann Surg Oncol 22: 1153-1159, 2015.

49. Ferrone CR, Marchegiani G, Hong TS, Ryan DP, Deshpande V, McDonnell EI, Sabbatino F, Santos DD, Allen JN, Blaszkowsky LS, et al: Radiological and surgical implications of neoadjuvant treatment with FOLFIRINOX for locally advanced and borderline resectable pancreatic cancer. Ann Surg 261: $12-17,2015$

50. Von Hoff DD, Ervin T, Arena FP, Chiorean EG, Infante J, Moore M, Seay T, Tjulandin SA, Ma WW, Saleh MN, et al: Increased survival in pancreatic cancer with nab-paclitaxel plus gemcitabine. N Engl J Med 369: 1691-1703, 2013.

51. Alvarez R, Musteanu M, Garcia-Garcia E, Lopez-Casas PP, Megias D, Guerra C, Muñoz M, Quijano Y, Cubillo A, Rodriguez-Pascual J, et al: Stromal disrupting effects of nab-paclitaxel in pancreatic cancer. Br J Cancer 109: 926-933, 2013.

52. Chiorean EG and Von Hoff DD: Taxanes: Impact on pancreatic cancer. Anticancer Drugs 25: 584-592, 2014.

53. Shinchi H, Takao S, Noma H, Matsuo Y, Mataki Y, Mori S and Aikou T: Length and quality of survival after external-beam radiotherapy with concurrent continuous 5-fluorouracil infusion for locally unresectable pancreatic cancer. Int J Radiat Oncol Biol Phys 53: 146-150, 2002.

54. Van Laethem JL,Hammel P,Mornex F, Azria D, Van Tienhoven G, Vergauwe P, Peeters M, Polus M, Praet M, Mauer M, et al: Adjuvant gemcitabine alone versus gemcitabine-based chemoradiotherapy after curative resection for pancreatic cancer: A Randomized EORTC-40013-22012/FFCD-9203/GERCOR Phase II Study. J Clin Oncol 28: 4450-4456, 2010.

55. Heinrich S, Pestalozzi BC, Schäfer M, Weber A, Bauerfeind P, Knuth A and Clavien PA: Prospective phase II trial of neoadjuvant chemotherapy with gemcitabine and cisplatin for resectable adenocarcinoma of the pancreatic head. J Clin Oncol 26: 2526-2531, 2008.

56. Heinrich S, Pestalozzi B, Lesurtel M, Berrevoet F, Laurent S, Delpero JR, Raoul JL, Bachellier P, Dufour P, Moehler M, et al: Adjuvant gemcitabine versus NEOadjuvant gemcitabine/oxaliplatin plus adjuvant gemcitabine in resectable pancreatic cancer: A randomized multicenter phase III study (NEOPAC study). BMC Cancer 11: 346, 2011.

57. Sho M, Akahori T, Tanaka T, Kinoshita S, Tamamoto T, Nomi T, Yamato I, Hokuto D, Yasuda S, Kawaguchi C, et al: Pathological and clinical impact of neoadjuvant chemoradiotherapy using full-dose gemcitabine and concurrent radiation for resectable pancreatic cancer. J Hepatobiliary Pancreat Sci 20: 197-205, 2013.

58. Van Buren G II, Ramanathan RK, Krasinskas AM, Smith RP, Abood GJ, Bahary N, Lembersky BC, Shuai Y, Potter DM, Bartlett DL, et al: Phase II study of induction fixed-dose rate gemcitabine and bevacizumab followed by 30 Gy radiotherapy as preoperative treatment for potentially resectable pancreatic adenocarcinoma. Ann Surg Oncol 20: 3787-3793, 2013.

59. Evans DB, Rich TA, Byrd DR, Cleary KR, Connelly JH, Levin B, Charnsangavej C, Fenoglio CJ and Ames FC: Preoperative chemoradiation and pancreaticoduodenectomy for adenocarcinoma of the pancreas. Arch Surg 127: 1335-1339, 1992.

60. Mahadevan D and Von Hoff DD: Tumor-stroma interactions in pancreatic ductal adenocarcinoma. Mol Cancer Ther 6: 1186-1197, 2007

61. Okamoto K, Tajima H, Ohta T, Nakanuma S, Hayashi H, Nakagawara H, Onishi I, Takamura H, Ninomiya I, Kitagawa $\mathrm{H}$, et al: Angiotensin II induces tumor progression and fibrosis in intrahepatic cholangiocarcinoma through an interaction with hepatic stellate cells. Int J Oncol 37: 1251-1259, 2010. 
62. Galván JA, Zlobec I, Wartenberg M, Lugli A, Gloor B, Perren A and Karamitopoulou E: Expression of E-cadherin repressors SNAIL, ZEB1 and ZEB2 by tumor and stromal cells influences tumor-budding phenotype and suggests heterogeneity of stromal cells in pancreatic cancer. Br J Cancer 112: 1944-1950, 2015.

63. Heeg S, Das KK, Reichert M, Bakir B, Takano S, Caspers J, Aiello NM, Wu K, Neesse A, Maitra A, et al: ETS-Transcription Factor TTV1 regurates stromal expansion and metastasis in pancreatic cancer. Gastroenterology 151: 540-553.e14, 2016.

64. Karnevi E, Rosendahl HA, Hilmersson SK, Saleem AM and Andersson R: Impact by pancreatic stellate cells on epithelial-mesenchymal transition and pancreatic cancer cell invasion: Adding a third dimension in vitro. Exp Cell Res 346: 206-215, 2016

65. Yang J, Mani SA, Donaher JL, Ramaswamy S, Itzykson RA, Come C, Savagner P, Gitelman I, Richardson A and Weinberg RA: Twist, a master regulator of morphogenesis, plays an essential role in tumor metastasis. Cell 117: 927-939, 2004.

66. Goses MJ, Dressen RC, Rutten HJ, Nieuwenhuijzen GA, van der Laak JA, Martijn H, Tan-Go I, Nagtegaal ID, van den Brule AJ and van Krieken JH: Preoperative radiochemotherapy is successful also in patients with locally advanced rectal cancer who have intrinsically high apoptotic tumors. Ann Oncol 19: 2026-2032, 2008.

67. Yang AD, Fan F, Camp ER, van Buren G, Liu W, Somcio R, Gray MJ, Cheng H, Hoff PM and Ellis LM: Chronic oxaliplatin resistance induces epithelial-to-mesenchymal transition in colorectal cancer cell lines. Clin Cancer Res 12: 4147-4153, 2006.

68. Tsukamoto H, Shibata K, Kajiyama H, Terauchi M, Nawa A and Kikkawa F: Irradiation-induced epithelial-mesenchymal transition (EMT) related to invasive potential in endometrial carcinoma cells. Gynecol Oncol 107: 500-504, 2007.

69. Tajima H, Ohta T, Makino I, Hayashi H, Nakagawara H, Onishi I, Takamura H, Ninomiya I, Kitagawa H, et al: Expression of epithelial-mesenchymal transition markers in locally recurrent hepatocellular carcinoma after radiofrequency ablation. Exp Therap Med 1: 347-350, 2010.

70. Tajima H, Ohta T, Kitagawa H, Okamoto K, Sakai S, Kinoshita J, Makino I, Furukawa H, Hayashi H, Nakamura K, et al: Neoadjuvant chemotherapy with gemcitabine for pancreatic cancer increases in situ expression of the apoptosis marker M30 and stem cell marker CD44. Oncol Let 3: 1186-1190, 2011.

71. Zhang D, Sun L, Xian W, Liu F, Ling G, Xiao L, Liu Y, Peng Y, Haruna Y and Kanwar YS: Low-dose paclitaxel ameliorates renal fibrosis in rat UUO model by inhibition of TGF-beta/Smad activity. Lab Invest 90: 436-447, 2010

72. Zhou J, Zhong DW, Wang QW, Miao XY and Xu XD: Paclitaxel ameliorates fibrosis in hepatic stellate cells via inhibition of TGF-beta/Smad activity. World J Gastroenterol 16: 3330-3334, 2010.

73. Choi HS, Savard CE, Choi JW, Kuver R and Lee SP: Paclitaxel interrupts TGF-beta1 signaling between gallbladder epithelial cells and myofibroblasts. J Surg Res 141: 183-191, 2007.

74. Hirose A, Tajima H, Ohta T, Tsukada T, Okamoto K, Nakanuma S, Sakai S, Kinoshita J, Makino I, Furukawa H, et al: Low-dose paclitaxel inhibits the induction of epidermal-mesenchymal transition in the human cholangiocarcinoma CCKS-1 cell line. Oncol Lett 6: 915-1920, 2013.

75. Cufí S, Vazquez-Martin A, Oliveras-Ferraros C, Martin-Castillo B and Joven J and Menendez JA: Metformin against TGF $\beta$-induced epithelial-to- mesenchymal transition (EMT): From cancer stem cells to aging-associated fibrosis. Cell Cycle 9: 4461-4468, 2010.

76. Vazquez-Martin A, Oliveras-Ferraros C, Cufí S, Del Barco S, Martin-Castillo B and Menendez JA: Metformin regulates breast cancer stem cell ontogeny by transcriptional regulation of the epithelial-mesenchymal transition (EMT) status. Cell Cycle 9: 3807-3814, 2010

77. Del Barco S, Vazquez-Martin A, Cufí S, Oliveras-Ferraros C, Bosch-Barrera J, Joven J, Martin-Castillo B and Menendez JA: Metformin: Multi-faceted protection against cancer. Oncotarget 2: 896-917, 2011.

78. Okazaki M, Fushida S, Harada S, Tsukada T, Kinoshita J, Oyama K, Tajima H, Ninomiya I, Fujimura T and Ohta T: The angiotensin II type 1 receptor blocker candesartan suppresses proliferation and fibrosis in gastric cancer. Cancer Lett 355: $46-53,2014$.
79. Chang TI, Kang HY, Kim KS, Lee SH, Nam BY, Paeng J, Kim S, Park JT, Yoo TH, Kang SW and Han SH: The effect of statin on epithelial-mesenchymal transition in peritoneal mesothelial cells. PLoS One 9: e109628, 2014.

80. Yang $T$, Chen $M$ and Sun T: Simvastatin attenuates TGF- $\beta 1$-induced epithelial-mesenchymal transition in human alveolar epithelial cells. Cell Physiol Biochem 31: 863-874, 2013.

81. Shoji M, Ninomiya I, Makino I, Kinoshita J, Nakamura K, Oyama K, Nakagawara H, Fujita H, Tajima H, Takamura H, et al: Valproic acid, a histone deacetylase inhibitor, enhances radiosensitivity in esophageal squamous cell carcinoma. Int J Oncol 40: 2140-2146, 2012

82. Watanabe T, Tajima H, Hironori H, Nakagawara H, Ohnishi I, Takamura H, Ninomiya I, Kitagawa H, Fushida S, Tani T, et al: Sodium valproate blocks the transforming grow th factor (TGF)- $\beta 1$ autocrine loop and attenuates the TGF- $\beta 1$-induced collagen synthesis in a human hepatic stellate cell line. Int J Mol Med 28: 919-925, 2011.

83. Lee MS, Hsu CC, Wahlqvist ML, Tsai HN, Chang YH and Huang YC: Type 2 diabetes increases and metformin reduces total, colorectal, liver and pancreatic cancer incidences in Taiwanese: A representative population prospective cohort study of 800,000 individuals. BMC Cancer 11-20, 2011.

84. Li D, Yeung SC, Hassan MM, Konopleva M and Abbruzzese JL: Antidiabetic therapies affect risk of pancreatic cancer. Gastroenterology 137: 482-488, 2009.

85. Nakai Y, Isayama H, Ijichi H, Sasaki T, Sasahira N, Hirano K, Kogure H, Kawakubo K, Yagioka H, Yashima Y, et al: Inhibition of renin-angiotensin system affects prognosis of advanced pancreatic cancer receiving gemcitabine. Br J Cancer 103: 1644-1648, 2010.

86. Sun JD, Liu Q, Ahluwalia D, Li W, Meng F, Wang Y, Bhupathi D, Ruprell AS and Hart CP: Efficacy and safety of the hypoxia-activated prodrug TH-302 in combination with gemcitabine and nab-paclitaxel in human tumor xenograft models of pancreatic cancer. Cancer Biol Ther 16: 438-449, 2015.

87. Zhang D, Yang R, Wang S and Dong Z: Paclitaxel: New uses for an old drug. Drug Des Devel Ther 8: 279-284, 2014

88. Meng H, Wang M, Liu H, Liu X, Situ A, Wu B, Ji Z, Chang CH and Nel AE: Use of a lipid-coated mesoporous silica nanoparticle platform for synergistic gemcitabine and paclitaxel delivery to human pancreatic cancer in mice. ACS Nano 9: 3540-3557, 2015.

89. Oettle H: Progress in the knowledge and treatment of advanced pancreatic cancer: From benchside to bedside. Cancer Treat Rev 40: 1039-1047, 2014.

90. Iwahashi S, Utsunomiya T, Imura S, Morine Y, Ikemoto T, Arakawa Y, Saito Y, Ishikawa D and Shimada M: Effects of valproic acid in combination with $\mathrm{S}-1$ on advanced pancreatobiliary tract cancers: Clinical study phases I/II. Anticancer Res 34: 5187-5191, 2014.

91. Poste G and Greig R: On the genesis and regulation of cellular heterogeneity in malignant tumors. Invasion Metastasis 2: 137-176, 1982 .

92. Hindriksen S and Bijlsma MF: Cancer stem cells, EMT, and developmental pathway activat ion in pancreatic tumors. Cancers (Basel) 4: 989-1035, 2012.

93. Jones S, Zhang X, Parsons DW, Lin JC, Leary RJ, Angenendt $P$, Mankoo P, Carter H, Kamiyama H, Jimeno A, et al: Core signaling pathways in human pancreatic cancers revealed by global genomic analyses. Science 321: 1801-1806, 2008.

94. Xu X, Rao GS, Groh V, Spies T, Gattuso P, Kaufman HL, Plate J and Prinz RA: Major histocompatibility complex class I-related chain A/B (MICA/B) expression in tumor tissue and serum of pancreatic cancer: Role of uric acid accumulation in gemcitabine-induced MICA/B expression. BMC Cancer 11: 194, 2011.

95. Miyashita T, Tajima H, Shoji M, Nakanuma S, Sakai S, Makino I, Hayashi $\mathrm{H}$, Nakagawara $\mathrm{H}$, Takamura $\mathrm{H}$, Kitagawa $\mathrm{H}$ and Ohta T: Gemcitabine augments major histocompatibility complex class I-related chain A expression in pancreatic cancer. Gan To Kagaku Ryoho 40: 1600-1602, 2013 (In Japanese).

96. Waldhauer I, Goehlsdorf D, Gieseke F, Weinschenk T, Wittenbrink M, Ludwig A, Stevanovic S, Rammensee HG and Steinle A: Tumor-associated MICA is shed by ADAM proteases. Cancer Res 68: 6368-6376, 2008.

97. Ashiru O, Boutet P, Fernández-Messina L, Agüera-González S, Skepper JN, Valés-Gómez M and Reyburn HT: Natural killer cell cy totoxicity is suppressed by exposure to the human NKG2D ligand MICA*008 that is shed by tumor cells in exosomes. Cancer Res 70: 481-489, 2010. 
98. Chitadze G, Lettau M, Bhat J, Wesch D, Steinle A, Fürst D, Mytilineos J, Kalthoff H, Janssen O, Oberg HH and Kabelitz D: Shedding of endogenous MHC class I-related chain molecules A and B from different human tumor entities: Heterogeneous involvement of the 'a disintegrin and metalloproteases' 10 and 17. Int J Cancer 133: 1557-1566, 2013.

99. Penafuerte C, Bautista-Lopez N, Bouchentouf M, Birman E, Forner K and Galipeau J: Novel TGF-beta antagonist inhibits tumor growth and angiogenesis by inducing IL-2 receptor-driven STAT1 activation. J Immunol 186: 6933-6944, 2011.

100. Lu J, Shi J, Li M, Gui B, Fu R, Yao G, Duan Z, Lv Z, Yang Y, Chen Z, et al: Activation of AMPK by metformin inhibits TGF- $\beta$-induced collagen production in mouse renal fibroblasts. Life Sci 127: 59-65, 2015.
101. Pscherer S, Freude T, Forst T, Nussler AK, Braun KF and Ehnert S: Anti-diabetic treatment regulates pro-fibrotic TGF- $\beta$ serum levels in type 2 diabetics. Diabetol Metab Syndr 5: 48 , 2013.

102. Pühringer-Oppermann F, Sarbia M, Ott N and Brücher BL: The predictive value of genes of the TGF-betal pathway in multimodally treated squamous cell carcinoma of the esophagus. Int J Colorectal Dis 25: 515-521, 2010. 